\section{W.J. Henderson}

W. J. Henderson is ' $n$ emeritusprofessor in die Departement Griekse en Latynse Studies, Universiteit van Johannesburg, Johannesburg. E-pos: ibycus@yebo.co.za

\title{
'n Nuwe gedig van Sappho
}

\section{A new Sappho poem}

The publication in 2004 of twenty-six lines of verse by the ancient Greek poet Sappho solves several questions surrounding Fragment 58 Lobel-Page, based on a papyrus dating from the 3rd century A.D. and published in 1922. This papyrus preserved only the righthand side of a poem or poems. The new discovery, on the papyrus cartonnage of a mummy at the University of Cologne, dates from the 3rd century B.C., contains the oldest Sappho text to date and offers what is virtually the lefthand side of one poem and some lines of two other poems. From the integration of the two texts an entire new poem of 12 lines has been recovered. The two papyri were written about 500 years apart - an indication of the sustained interest in this great poet. The present article gives some of the background on the poetess and the new discovery, and offers an Afrikaans translation and analysis of the new poem. The poem deals with the physical and psychological effects of advancing age, and in its directness and realism recalls Sappho's Fragment 31 Lobel-Page. To enhance her theme, she uses the mythological example of the dawngoddess Eos who loved the mortal Tithonus and obtained immortality for him - but without eternal youth. So Tithonus grew ever older while Eos remained young. The example is meant to prove human mortality, and poignantly contrasts Sappho's situation with that of the young girls in her care. Key words: Sappho, ancient Greek lyric poetry, old age, papyrus cartonnage.

\section{Inleiding}

Opgewondenheid heers onder navorsers en liefhebbers van die antieke Griekse poësie. 'n Nuwe gedig van die digteres Sappho van Lesbos het in 2004 aan die lig gekom, meer as 2600 jaar na haar leeftyd (ongeveer 600 v.C.). ${ }^{1}$ In antieke tye was sy reeds bewonder as een van die nege grootste liriese digters; en in die biblioteek van Alexandrië was daar nege boekrolle van haar liriese poësie. Deur die eeue het haar aansien en belangrikheid in die geskiedenis van die Griekse en Westerse liriese poësie gedy, ten spyte van die feit dat net fragmente van haar oeuvre bewaar is (vgl. Henderson 2004: 79-112).

Antieke tekste van liriese digters is en word teruggevind in ander skrywers, soos kritici en teoretici, wat hulle as illustrasie aanhaal, of op papirus uit die Saharawoestyn. In albei gevalle is die tekste fragmentaries, net' $n$ stukkie van die oorspronklike gedig. In Sappho se geval is daar 264 genommerde fragmente, sommige net verwysing na wat sy sou gesê het, of net enkele woorde of reëls; net 63 het volledige reëls, net 21 volledige strofes. Ongeveer $30 \%$ van die fragmente is op papirus herwin, en 
$70 \%$ is uit ander skrywers se werke teruggevind. Tot onlangs was daar net drie wat lank genoeg is om behoorlik ontleed te word. Daar is die gelukkige geval van Fr. 1, wat aan Aphrodite gerig is en byna volledig deur Dionusios van Halikarnassos (1ste eeu v.C.-1ste eeu n.C.) aangehaal en bespreek is (vgl. Henderson 2004: 81-84); of van Fr. 31, wat ook met vertolking deur "Longinus" aangehaal is (vgl. Henderson 2004: 8788). Dan is daar die wonderbaarlike geval van Fr. 2, wat op'n potskerf (ostrakon) uit die 3de eeu v.C. teruggevind en in 1937 gepubliseer is (tans in Florence) (vgl. Henderson 2004: 97-98).

In 1922 is 'n papirus wat in Oxyrhynchus (el-Bahnasa) in Egipte gevind is en uit die 3de eeu n.C. dateer, gepubliseer (P. Oxy. 15.1787). ${ }^{2}$ Die brokstukke van liriese verse daarop het uiteindelik Sappho, Fr. 58 Lobel-Page geword (Lobel \& Page, 1955). Die bewaarde stuk was die afgeskeurde regterkant van die papirus; die linkerkant, met die aanvang van die versreëls en aanduidings van strofes en einde van gedig, was weg. Twee reëls aan die einde (25-26) stem ooreen met'n sitaat van Athenaios (687b). ${ }^{3}$ Geleerdes het geworstel om uit die oorblyfsels sin te maak, veral omdat algemeen aanvaar is dat die reëls almal aan dieselfde gedig behoort. ${ }^{4}$ Die nuwe vonds bied antwoorde op baie van die vrae.

In 2004 publiseer Michael Gronewald en Robert Daniel van die Universiteit van Keulen drie papirusfragmente, P. Colon. 21351 (twee fragmente), en 21376, wat uit die 3de eeu v.C. dateer, drie eeue ná Sappho. Dit is die oudste bestaande Sappho-teks (Gronewald \& Daniel, 2004a, 2004b). Die papirus is teruggewin van die omhulsel (cartonnage) van'n Egiptiese mummie. Dit was algemene praktyk om mummies met ou stukke droeë papirus op te stop, en met geweekte velle die omhulsel in lae op te bou sodat die kontoere van die liggaam weergegee is. Besonderhede van gesig, versiering en kleding is dan daarop geverf. ${ }^{5}$ Aan die een kant van die nuwe papirusfragmente is nog gips en spore van kleur te bespeur; aan die ander kant is altesaam 26 versreëls herwin. Aan die linkerkant van die papirus word tweereëlige strofes met' $n$ paragraphos (-) aangedui; ' $n$ koronis ('n haal van die pen wat lyk soos 'n 2 met 'n verlengde voet) in die linkerkantste kantlyn by reël 21 en' $n$ gaping tussen reëls 20 en 21 merk onteenseglik die einde van'n gedig. ${ }^{6}$ Reëls $9-20$ sluit aan by 12 reëls van die Oxyrhynchus-papirus (11-22), maar die reëls voor en na hierdie twaalf verskil totaal in die twee papiri. Dit beteken dat die gemeenskaplike gedeelte' $n$ aparte gedig is wat tot nog toe onbekend was, en nou die vierde lang en byna volledige gedig van Sappho is. Nog' $n$ wins is die gedeeltelike bewaring van die slotverse van ' $n$ tot nog toe onbekende Sappho-gedig. Die twee papirusse bied nou verdere insae in die oorleweringsgeskiedenis van Sappho se gedigte. Ons word gekonfronteer met twee verskillende "uitgawes" van haar poësie, met iets soos 500 jaar tussenin - 'n werklik verstommende stuk informasie. ${ }^{7}$ 


\section{Vertaling}

[Die Muses, purper] gegordel, se mooi geskenke, dogters,

[ ] die liedliewende, helderklinkende lier.

[My gerimpelde] vel, eens [sag,] het die ouderdom nou [beetgekry, en wit] het my hare geword van swart, ${ }^{8}$

my gemoed het swaar geword, my knieë dra my nie, wat eens vlugtig was om te dans net soos bokkies.

Hieroor kla ek dikwels, maar wat kan 'n mens doen? Om ouderdomloos te wees, én mens, is onmoontlik.

So is vertel dat roosarmige Eos eens uit liefde vir Tithonos die beker bestyg en hom na die ent van die wêreld gevoer het,

mooi en jonk toe, maar gryse ouderdom het hom tog mettertyd ingehaal, terwyl hy 'n onsterflike vrou besit. ${ }^{9}$

\section{Bespreking}

Meestal dig Sappho in haar kenmerkende strofes van vier reëls elk (byvoorbeeld Fr. 31), maar daar is ook gedigte met strofes van net drie reëls (Frr. 94, 95, 96, 98), asook met twee reëls soos in die huidige geval (Frr. 43, 62, 63, 65, 66, 67, 82b). ${ }^{10}$

Die aanvang van die eerste vier reëls ontbreek, maar in die eerste reël kan die Muses met vertroue aangevul word: hulle gawes is in hierdie konteks veral grasie, insig, musiek en dans. ${ }^{11}$ Die byvoeglike naamwoord wat op hulle toegepas word (iokolpos), kan verwys na'n mantel, of na'n gordel van regte viooltjies of net in die kleur purper. ${ }^{12}$ Daar is besondere beklemtoning van die lier: die dubbele adjektiewe is seldsaam (Gronewald \& Daniel 2004a: 7). Die ander gapings word verskillend aangevul: Gronewald \& Daniel meen die digter verklaar dat sy die gawes van die Muses bring, en dat sy nou die lier opneem om te speel en sing; ${ }^{13}$ West (2005) suggereer dat die digter die dogters maan om die gawes van die Muses na te streef. ${ }^{14}$ Die moontlike variante van letters in die gapings is te veel om op hierdie stadium sekerheid te bereik oor die teks. Die dogters is die jong adolessente meisies uit aristokratiese families wat aan Sappho se toesig toevertrou is om hulle vir hulle lewens as vrouens en moeders gereed te maak (vgl. Henderson 2004: 79-81). Aan hierdie jong lede van haar kring (thiasos) het die digteres lierspel, dans en ander vaardighede en kennis oorgedra. Die didaktiese inslag van haar poësie blyk duidelik in hierdie reëls soos in die res van haar oeuvre. 
Die simptome van ouderdom (vel wat verrimpel, hare wat wit word, gemoed wat swaar word, knieë wat verswak, 3-6) kom sonder waarskuwing, en skep so 'n sterk kontras met die eerste twee reëls. Die simptome is natuurlik gekies om die liggaamlike aftakeling grafies te tipeer, en lyk vir ons taamlik geyk. Nadere ondersoek wys egter dat dit alles behalwe die geval is. Vóór Sappho beskryf Archilochos (middel 7de eeu v.C.) die effek van ouderdom op'n vrou se voorkoms, veral haar vel; en ná Sappho verwys Aristophanes (c. 445 -c. 385 v.C.) eers weer daarna. ${ }^{15}$ Daarteenoor kom grys of wit hare dikwels voor, ${ }^{16}$ maar die metafoor in "gryse ouderdom" verskyn hier vir die eerste maal in bestaande Griekse letterkunde. ${ }^{17}$ Wat betref die "gemoed" (thumos) wat swaar word, gebruik Sappho self die woord elders, in Fr. 42.1, waar sy praat van duiwe wat hulle vlerke verslap as hulle harte "koud" word (vgl. Henderson 2004: 90). Ongeveer twee dekades vóór Sappho dig Mimnermos (aktief c. 632 v.C.) van die "hart" (thumos) wat met die koms van ouderdom deur verlies van inkomste, kinderloosheid en siektes geteister word (Fr. 2.11-15). So lyk hy na die eerste digter in Grieks om die effek van ouderdom op die psige te beskryf (Bernsdorff 2004: 32-33). Die kombinasie "swaar gemoed" (barus thumos) verskyn egter nie voor Sappho nie, en dan ná haar eers weer by Theokritos (c. 300-c.260 v.C.) in sy Idille 1.96 (Bernsdorff 2004: 30). Die laaste een, die swak knieë, kom wel vóór Sappho voor: die digter Alkman (aktief c. 654-611 v.C.), wat meisieskore afgerig het, praat ook van sy bene wat hom nie meer wil dra nie (Fr. 26 Page = PMG 26.1-2). ${ }^{18}$ Sappho brei egter die simptoom uit met die vergelyking met ligvoetige jong herte. Daarin kan ons sien hoe geliefd dans in die kring was, en hoe sy met weemoed daarvan moet afskeid neem.

Drie simptome is kennelik fisies: bepaalde liggaamsdele (vel, hare, knieë) word aangetas. Met die gemoed (thumos) is dit anders. Al het die antieke mens geglo en gevoel dit setel in die hart, betrek dit nie ' $n$ bepaalde deel van die liggaam nie, maar'n oorkoepelende gevoel wat die hele liggaam affekteer. Bernsdorff (2004: 27-28) het oortuigend betoog dat thumos in geestelike terme as Schwermut verstaan moet word. Dit is seer sekerlik nie fisies in die sin van ' $n$ hartkwaal nie, maar eerder iets soos 'n fisiese gevoel van moegheid wat die liggaam laat swaar voel. Dit moet dus in die konteks van die koeplet, saam met die moeisame treë, vertolk word.

Ook die kombinasie van die simptome is uniek en vertoon tekens van eie ervaring en oorspronklike komposisie. As die aanvullings in reëls 3-4 korrek is, blyk dit dat elkeen van die simptome, behalwe die gemoed, met hulle teenoorgesteldes gebalanseer word: gerimpelde teenoor sagte vel; wit teenoor swart hare; swak teenoor vlugtige knieë. ${ }^{19}$ So teken die digter in 'n verbasend ekonomiese en beheersde styl die verskil tussen hoe sy eens was en nou is. En ons weet van haar beroemde gedig (Fr. 31) oor die effek van liefdespassie hoe persoonlik en intiem sy simptome kan uitdruk. Hierdie beskrywing van ouderdom is net so'n persoonlike bekentenis: Sappho kyk na haarself en beskryf wat sy sien (Gronewald \& Daniel 2004a: 3).

In die volgende koeplet (7-8) bieg die digter dat sy oor die ouderdom kla, maar 
besef ook dat dit'n onafwendbare deel van menslike bestaan is. Die segging is eenvoudig en direk, maar die woord wat hier met "ouderdomloos" vertaal is, is iets nuuts in die liriek. ${ }^{20}$ As "bewyse" hiervoor gebruik sy die mitologiese voorbeeld van Tithonos, op wie die Oggendgodin (Eos) verlief geraak het (9-12). Op haar versoek maak Zeus hom onsterflik. Ongelukkig het sy nie vir ewige jonkheid daarby gevra nie, en haar eggenoot het al hoe ouer en kleiner geword terwyl sy ewig jonk bly. Uiteindelik het sy hom in ' $n$ kamer toegesluit om van sy nimmereindigende klagtes te ontsnap (Gronewald \& Daniel 2004a: 2).

Dit is die vroegste bestaande gebruik van die vergelyking. ${ }^{21}$ Dit word hier meer verhewe gemaak deur die gebruik van die byvoeglike naamwoord "roosarmig" wat op Eos toegepas word, ${ }^{22}$ en ook deur die verwysing na die "beker", kennelik die beker waarin die son elke nag van die weste terug na die ooste op die omringende water om die aarde gevaar het. Digters voor Sappho het ook na hierdie beker verwys. Nuut is egter die gegewe dat Eos dit gebruik om na die uiteindes van die aarde te vaar, dit is Okeanos (die Atlantiese Oseaan), in die weste. ${ }^{23}$ Aan die einde voel ons die diep patos in die verwysing na die ewigskone, ewigjonge bruid. Dit word verskerp deur die besef dat die digter soos Tithonos oud word, terwyl om haar die dogters skynbaar altyd soos Eos jong bruide bly.

\section{Gevolgtrekkings}

Die nuwe gedig bring bevestiging van wat ons reeds van Sappho weet. Die konteks is bekend: die thiasos waar die meisies van die Muses se gawes, lierspel en dans, leer. Hierdie teks vertoon ook die bekende eienskappe wat deur Dionusios van Halikarnassos reeds in Fr. 1 raakgesien het: die fyn afwerking, welluidendheid en sjarme wat die gevolg is van die korrekte plasing van woorde en die kohesie en gladheid van oorgange (Dion. Halik., De compositione verborum 23; Campbell 1990: 52-55); of wat "Longinus" in Fr. 31 gevind het: Sappho se keuse van besonderhede uit'n werklike situasie en die kombinasie van die belangrikstes in 'n patroon van kontrastering (Ps.Long., De sublimitate 10.1-3; Campbell 1990: 78-81). Daarby kan gevoeg word haar beheersde, eenvoudige styl, treffende beeldspraak en oorspronklike stem.

Daar is ook nuwe kennis en insigte. Die eerste is die oplossing van die indeling van die gedigte wat voorheen as Fr. 58 saamgevoeg was. Die bestaande kennis van die oorleweringsgeskiedenis is ook aangevul. Die belangrikste aanwins is egter die gedig se tema, die behandeling van die ouderdom. Die literêre aspekte en waarde daarvan is reeds hierbo uitgelig. Daar is ook nuwe biografiese inligting. Uit antieke bronne leer ons dat Sappho getroud was en 'n dogter Kleïs gehad het, maar daar word geen melding van haar ouderdom of lewensduur gemaak nie (kyk Campbell 1990: 2-3). In enkele gedigte roep sy in herinnering die dae toe sy jonk was en sommige van die huidige gesiene vrouens nog as jong dogters lede van haar thiasos was (Frr. 24, 49, 96, 
125). ${ }^{24}$ In die brokstukke van Fr. 21 lees ons van die ouderdom wat reeds haar vel bedek. Nou het ons bevestiging dat Sappho'n gevorderde ouderdom bereik het. Dit kan aanvaar word dat die digter in haar eie persona praat (so meen ook Bernsdorff 2004: 32n): sy sing immers die gedig vir die meisies van die kring, en hulle sou dus die tekens van ouderdom kon gesien het. Dit lyk, teen die agtergrond van die lae gemiddelde lewensverwagting van die tyd (tussen 35 en 40 jaar), na 'n bogemiddelde lewensduur. Die tekens daarvan (plooie, wit hare, swak knieë en swaar gemoed) kom egter op verskillende ouderdomme by verskillende mense voor, en kan dus nie gebruik word om haar presiese ouderdom te bepaal nie.

Tegnologiese ontwikkelinge het hierdie ontdekking moontlik gemaak. Vroeër was argeoloë huiwerig om mummies oop te maak; daar was altyd die gevaar van verbrokkeling en skade. Nou kan die liggaam eers geskandeer word, en die omhulsel dan laag vir laag afgehaal en 'n fotografiese rekord gehou word. Die rekenaar word ingespan om driedimensionele voorstellinge te skep. Ook die lees van die teks op die antieke papirusvelle word verrig met elektroniese apparaat. Met hierdie hulpmiddels tot hulle beskikking is die kanse goed dat argeoloë nog meer dergelike vondse gaan maak op die talle mummies wat in die kelders van musea swygend lê.

\section{Aantekeninge}

1. Haar leeftyd lê êrens tussen 630 en 550 v.C. Vgl. Campbell 1990: x-xi, wat haar geboortedatum as c. 630 v.C. opgee.

2. Vir'n kaart, kyk Turner (1968: kaart 1a).

3. Athenaios van Naukratis in Egipte skryf in ongeveer 200 n.C., in dieselfde eeu as P. Oxy. 1787. Dis die laaste verwysing na hierdie besondere uitgawe van Sappho se gedigte. Ander kopieë kon egter vir lank daarna nog in sirkulasie gewees het. Hy plaas die woorde in die mond van Klearchos van Soli in Siprus (c. 340-c. 250 v.C.), wat weer in die tydvak van die Keulen-papirus is. Die Bisantynse veelskrywer Tzetzes (12de eeu n.C.) meld dat in sy tyd Sappho se werke verlore was (Oor Pindaros se metra 20-22; Campbell 1990: 50-51).

4. Vgl. die teks en vertaling van Campbell (1990: 100-01); en die bespreking van Preisshofen (1977: 5764). Vgl. ook die verbeeldingryke rekonstruksie van Edmonds, (1922: 434-37). Vir studies oor Fr. 58 vgl. Gerber (1993: 123).

5. Vir die hergebruik van papirus om mummies te vul of bind, vgl. Turner (1968: 24, 31, en plaat III); Reynolds \& Wilson (1968: 35-36); Dorandi \& Quack (2000: 301-303).

6. Oor die paragraphos, kyk Turner (1968: 184n); Kenyon (1970: 27) en Dorandi (1999: 90).

7. Vgl. Gronewald \& Daniel (2004a: 2). Volgens hulle is die vroegste uitgawe, die P. Col.,' $n$ bloemlesing wat volgens tema gerangskik is, en die latere een, die P. Oxy., 'n versameling van haar werk volgens alfabetiese ordening gerangskik.

8. West (2005: 8) vul aan en vertaal: "[but my once tender] body old age now / [has seized;] my hair's turned [white] instead of dark"; Gronewald \& Daniel (2004a: 5): "[Runzelig gemacht hat (?)] die einst [zarte] Haut [mir] das Alter schon, / [Furchen sind darin (?), weiß] geworden sind die Haare aus schwarzen" (Die ouderdom het my eens sagte vel reeds verrimpeld gemaak, / daar's plooie in, van swart het my hare wit geword).

9. Vgl. West (2005: 8) "Tithonus once, the tale was, rose-armed Dawn, / love-smitten carried off to the world's end, / handsome and young then, yet in time grey age / o'ertook him, husband of immortal wife"; Gronewald \& Daniel (2004b: 2): "Denn einst sagte man auch über Tithonos, daß die rosenarmige Eos / aus Liebesverlangen den (Sonnen)becher bestiegen habe, (ihn) zum Ende der Erde tragend, / schön seiend und jung, aber dennoch ergriff ihn / mit der Zeit das graue Alter, 
habend die unsterbliche Gattin" (Want eens het mense ook oor Tithonos gesê, dat the roosarmige Eos / uit liefdesverlange in the sonbeker geklim en hom na die einde van die aarde gevoer het, toe hy nog beeldskoon en jonk was, maar tog het die gryse ouderdom hom mettertyd gegryp, terwyl hy die onsterflike gemalin gehad het).

10. Sy het ook in nie-strofiese formaat (stiggies) gekomponeer (bv. Frr. 44, 49, 101, 102, 105, 112, 132). Vgl. ook die inligting van Hephaistion, Oor die poësie 1.2; Campbell, (1990: 28-31).

11. Vir die geskenke van die Muses, vgl. Archilochos, Fr. 1 West (1971); Alkman, Fr. 59b Page (1975); Solon, Fr. 13.51 West (1971); Theognis 250.

12. Sappho self gebruik die woord elders in verband met Aphrodite (Fr. 103.6, 7 en dalk ook Fr. 21.13) en ' $n$ bruid (Fr. 30.5). Die woord kolpos kan verwys na 'n boesem of skoot en dan 'n mantel impliseer; of na' $n$ vou in 'n rok, veral waar dit oor'n gordel val, en dan op die gordel self sinspeel.

13. Grondewald \& Daniel (2004a: 5): "[Ich bringe hier(?)] der purpergegürteten [Musen] schöne Gaben, Mädchen, / [wieder ergreifend (?)] die den Gesang liebende, helltönende Leier" (Ek bring hier die purper-gegordelde Muses se pragtige geskenke, meisies, as ek weer die sangliewende, helderklinkende lier opneem).

14. West (2005: 8): "You for the fragrant-blossomed Muses' lovely gifts / [be zealous,] girls, [and the] clear melodious lyre."

15. Archil., Fr. 188 West (1971); Aristoph., Plutus 1051. Plato verwys daarna in sy Symposium (190e), Aristoteles in sy Historia animalium (578a9) en Physiognomonica (808a8) en Hippokrates in sy Epidêmiai (6.1.13). Vgl. ook Gronewald \& Daniel (2004a: 3). In Homeros se Odusseia verander die godin Athena die voorkoms van Odusseus deur onder andere sy vel te verouder $(\mathrm{Od}$. 13.398) en dan weer te verjong $(O d$. 16.175). Oor die tema van ouderdom in die Griekse poësie, kyk Preisshofen 1977.

16. Homeros, Ilias 22.74; Odusseia 24.317, 499; Turtaios, Fr. 10.23; Anakreon, Fr. 50 Page (1975) = PMG 395.1-2; Sophokles, Antigone 1092; Aias 625; Oedipus Rex 182, 742.

17. Daarna by Pindaros, Isthmiese Ode 6.15; Bakchulides 3.88-89; Theognis 174; Euripides, Supplices 170; Ion 700; Bakchai 258; Simias, Anthologia Palatina 7.647.4; Leonidas, Anth. Pal. 7.726.4.

18. Vgl. verder Henderson (2004: 48-49); Gronewald \& Daniel (2004a: 7); Bernsdorff (2004: 33-34). Die bejaarde Nestor kla ook oor sy swak knieë (Hom., Il. 23.627), maar sy thumos, anders as Sappho s'n, is nog gewillig (Il. 4.313-16); vgl. Bernsdorff (2004: 29).

19. Volgens Bernsdorff (2004: 28) nog 'n aanduiding dat thumos anders as die ander simptome is.

20. Dit kom wel in Homeros en Hesiodos se poësie voor; vgl. Gronewald \& Daniel (2004a: 8).

21. Dit verskyn weer by Mimnermos, Fr. 4; Aristophanes, Acharnenses 688; Kallimachos, Jambe 1.249.

22. Sappho pas die term ook op die Grasië (Charites) toe (Fr. 53), terwyl Mimnermos Eos as "met rooskleurige vingers" beskryf (Fr. 12.3).

23. Vgl. Athenaios $11.469 \mathrm{c}-470 \mathrm{~d}$, wat ook die vroegste bestaande verwysing daarna in Stesichoros aanhaal (Fr. 8 Page = PMG 185); vgl. verder Henderson (2004: 55, 59). Vgl. ook Mimnermos, Fr. 12.5 West (1971) waar dit soos ' $n$ bed uitgebeeld word. Hoe die son sy vervoerprobleem die volgende oggend opgelos het, word verswyg, maar in mite is alles moontlik; vgl. Gronewald \& Daniel (2004b: 3).

24. Die wens om dood te gaan (Frr. 94 en 95) is nie weens ouderdom nie, maar verlange.

\section{Bronnelys}

Bernsdorff, Hans. 2004. Schwermut des Alters im neuen Kölner Sappho-Papyrus. Zeitschrift für Papyrologie und Epigraphik 150: 27-35.

Campbell, D.A. 1990 [1982]. Greek Lyric 1: Sappho and Alcaeus. Cambridge, Mass.: Harvard University Press.

Dorandi, T. \& Quack, J. 2000. Papyrus. In H. Cancik \& H. Schneider (reds.), Der Neue Pauly. Enzyklopädie der Antike, 9: 298-303. Stuttgart: Verlag J.B. Metzler.

Dorandi, T. 1999. Lesezeichen. In H. Cancik \& H. Schneider (reds.), Der Neue Pauly. Enzyklopädie der Antike, 7: 88-92. Stuttgart: Verlag J.B. Metzler.

Ezard, John. 2005. After 2,600 years, the world gains a fourth poem by Sappho. The Guardian, Friday June 24.

Gerber, D.E. 1993. Greek Lyric Poetry since 1920, Part I: General, Lesbian Poets. Göttingen: Vandenhoeck \& Ruprecht. 
Gronewald, Michael \& Daniel, Robert W. 2004a. Ein neuer Sappho-Papyrus. Zeitschrift für Papyrologie und Epigraphik 147: 1-8.

2004b. Nachtrag zum neuen Sappho-Papyrus. Zeitschrift für Papyrologie und Epigraphik 149: 1-4.

Henderson, W.J. 2004. Op Griekse Lier. Vroeë Griekse Liriese poësie, vertaal en toegelig. Pretoria: Protea Boekhuis.

Kenyon, F.G. 1970. The Palaeography of Greek Papyri. Chicago: Argonaut Inc.

Lobel, E. \& Page, D. 1955. Poetarum Lesbiorum Fragmenta. Oxford: Clarendon Press.

Page, D. 1975 [1962]. Poetae Melici Graeci. [PMG]. Oxford: Clarendon Press.

Preisshofen, F. 1977. Untersuchungen zur Darstellung des Greisenalters in der frühgriechischen Dichtung. Wiesbaden: Franz Steiner Verlag.

Reynolds, L.D. \& Wilson, N.G. 1968. Scribes and Scholars. A Guide to the Transmission of Greek and Latin Literature. Oxford: University Press.

Turner, E.G. 1968. Greek Papyri. An Introduction. Oxford: Clarendon Press.

West, M.L. 1971. Iambi et Elegi Graeci. Oxford: Clarendon Press.

West, Martin. 2005. A new Sappho poem. Times Literary Supplement, 24 June 8. 